Annual report on the project:

\title{
Nuclear Probing of Dense Plasmas and Implosion Physics at OMEGA, Z, OMEGA with EP, and the NIF
}

\author{
U.S. Department of Energy \\ Award Number: \\ DE-FG52-06NA26203
}

Recipient:

Massachusetts Institute of Technology

Cambridge, MA 02139

Principal Investigator:

Dr. Richard D. Petrasso

Plasma Science and Fusion Center

Massachusetts Institute of Technology

Cambridge, MA 02139

Tel: (617)253-8458

Fax: (617)258-7929

petrasso@psfc.mit.edu

Period covered:

15 February 2006 - 14 February 2007

Date of report:

15 May 2007 


\section{TABLE OF CONTENTS}

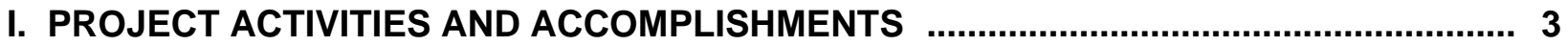

A. High resolution neutron spectroscopy for $\rho R$, Ti, and Yield

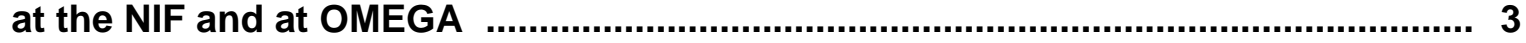

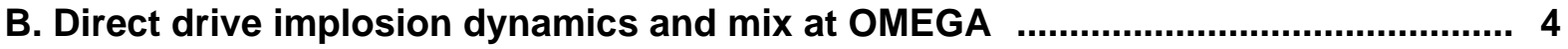

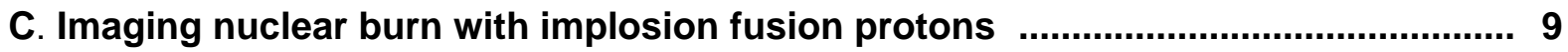

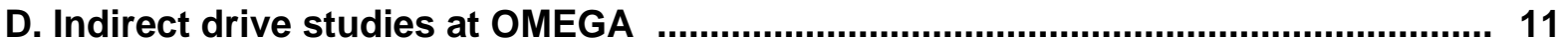

E. Graduate and undergraduate student training, education and research $\ldots . . . . . . . . . .12$

II. SCHEDULE AND COMPARISON OF ACCOMPLISHMENTS WITH OBJECTIVES $\ldots . . . . .12$

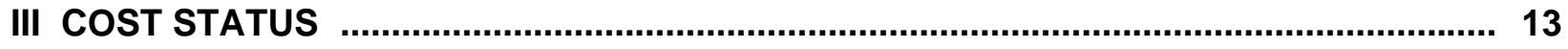

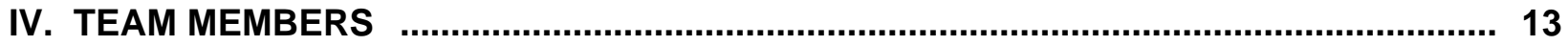

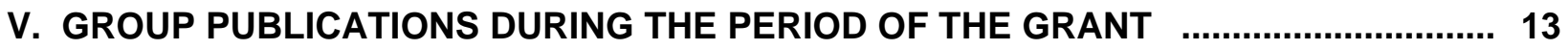

VI. GROUP CONFERENCE PRESENTATIONS DURING THE PERIOD OF THE GRANT . 16

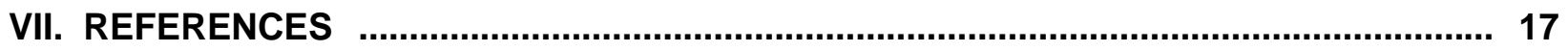

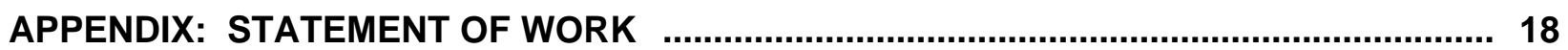




\section{PROJECT ACTIVITIES AND ACCOMPLISHMENTS}

The major subsections A - E below are numbered in correspondence with the major sections of the original Statement of Work, which is reproduced in the Appendix. In each case, we show here representative results of activities performed under the contract, but the full range of work and accomplishments is more completely represented by the large number of published papers listed in Sec. V and the conference presentations listed in Sec. VI.

\section{A. High resolution neutron spectroscopy for $\rho R, T i$, and Yield at the NIF and at OMEGA}

\section{i. Development of a NIF prototype neutron spectrometer at OMEGA}

Measurement of $\rho \mathrm{R}$ is fundamental to understanding the performance of any type of implosion $[1,2]$. MIT and collaborators have developed and utilized charged-particle diagnostics for determining $\rho R$ [3-12], but they will fail for $\rho \mathrm{R}>200 \mathrm{mg} / \mathrm{cm}^{2}$ and will therefore not work for the $\sim 300 \mathrm{mg} / \mathrm{cm}^{2}$ expected in upcoming OMEGA cryogenic DT implosions, or the $300-2000 \mathrm{mg} / \mathrm{cm}^{2}$ expected in NIF implosions. MIT therefore proposed and undertook the design of a unique high-resolution neutron spectrometer for measurements of primarily scattered neutrons, from which $\rho \mathrm{R}$ in the 100 to $2000 \mathrm{mg} / \mathrm{cm}^{2}$ range can be inferred [13-16].

After several reviews by National Laboratory participants and the DP office, MIT contracted Dexter Magnetic Technologies, a couple of years ago, to fabricate the most expensive component, which is a magnet. The MRS project at UR/LLE is now a program comprised of a couple concurrent efforts including the engineering of the MRS, and developing a new detection technique with improved signalto-background characteristics. With the commitment of LLE to engineer the interface of the spectrometer to OMEGA, we anticipate, according to plan, interfacing and qualifying the instrument on OMEGA in July this year.

The instrument is called the Magnetic Recoil Spectrometer (MRS) because of its operating principle, shown in Fig. 1a. The prototype ("OMEGA-MRS") and its planned interface on OMEGA have been designed, as shown in Fig. 1b. CR-39 will be used for particle detection. The nature of the spectra to be measured is illustrated in Fig. 2, which shows simulations from our LLNL collaborators for a cryogenic DT implosion at OMEGA $\left(\rho \mathrm{R} \approx 130 \mathrm{mg} / \mathrm{cm}^{2}\right)$, a NIF fizzle $\left(\rho \mathrm{R} \sim 1000 \mathrm{mg} / \mathrm{cm}^{2}\right)$, and an ignited capsule $\left(\rho \mathrm{R} \sim 1500 \mathrm{mg} / \mathrm{cm}^{2}\right)$. The MRS should be able to reliably measure all of these spectra for determination of $\rho R, T_{i}$, and absolute yield as described in Ref. 14.

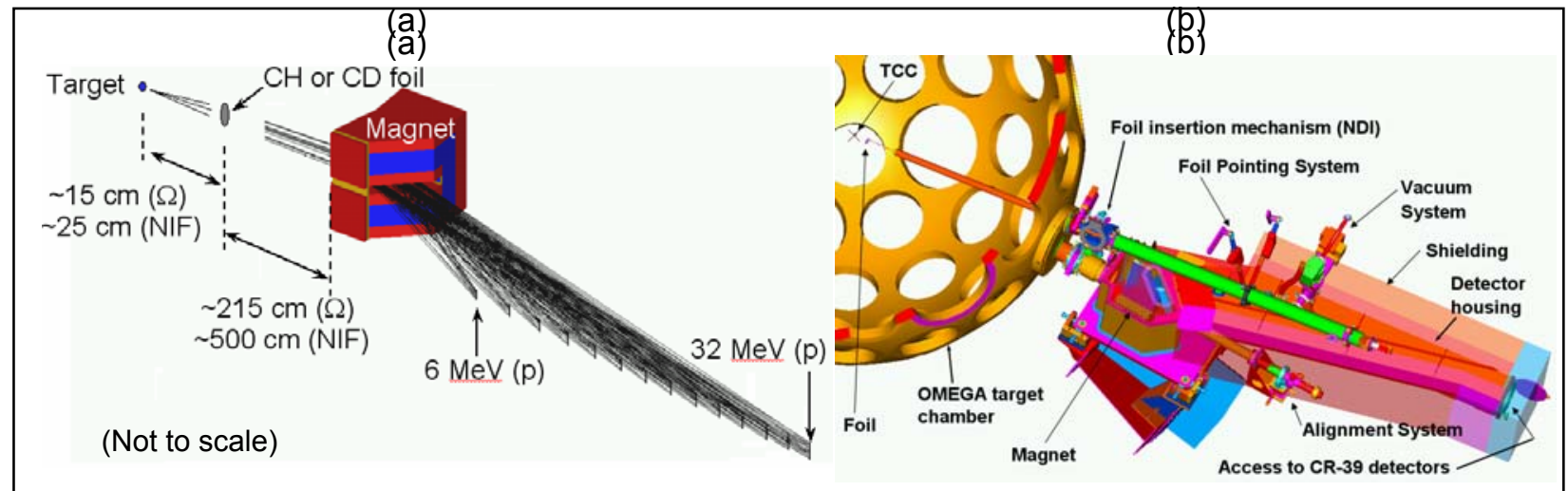

FIG. 1. (a) Principle of the Magnetic Recoil Spectrometer (MRS), which will be used to determine $\rho$ R, $T_{i}$, and the absolute neutron yield with high accuracy, first at OMEGA, then at the NIF. Forward scattered protons (or deuterons) from a $\mathrm{CH}$ foil (or $\mathrm{CD}$ foil) are momentum analyzed and focused by the magnet onto the detector. The magnet for the OMEGA system has been fabricated [13-16]. (b) Engineering design for MRS system on OMEGA. With the commitment of LLE to engineer the interface of the spectrometer to OMEGA, we anticipate interfacing and qualifying the instrument on OMEGA in July this year. 
The OMEGA-MRS is a replica and prototype of the MRS system we will to interface at the NIF in 2010 ("NIF-MRS") except for some rescaling of distances. The magnet, which is the core of the spectrometer, is virtually identical for both systems. Well before 2010 we must test, debug, and verify at OMEGA that all the necessary elements of the MRS are functioning flawlessly; these include the detector, the full system integration, the analysis programs, the instrument calibration, and the final instrument qualification. Very important to this process is cross calibration between MRS and charged particle measurements for cryogenic DT implosions with $\rho \mathrm{R} \sim 100$ to $200 \mathrm{mg} / \mathrm{cm}^{2}$, where both approaches will work. When cryogenic DT operates above $200 \mathrm{mg} / \mathrm{cm}^{2}$, only the MRS will be able to measure the $\rho R$; its utility will be unique and vital to implosion studies and the National ICF Program.

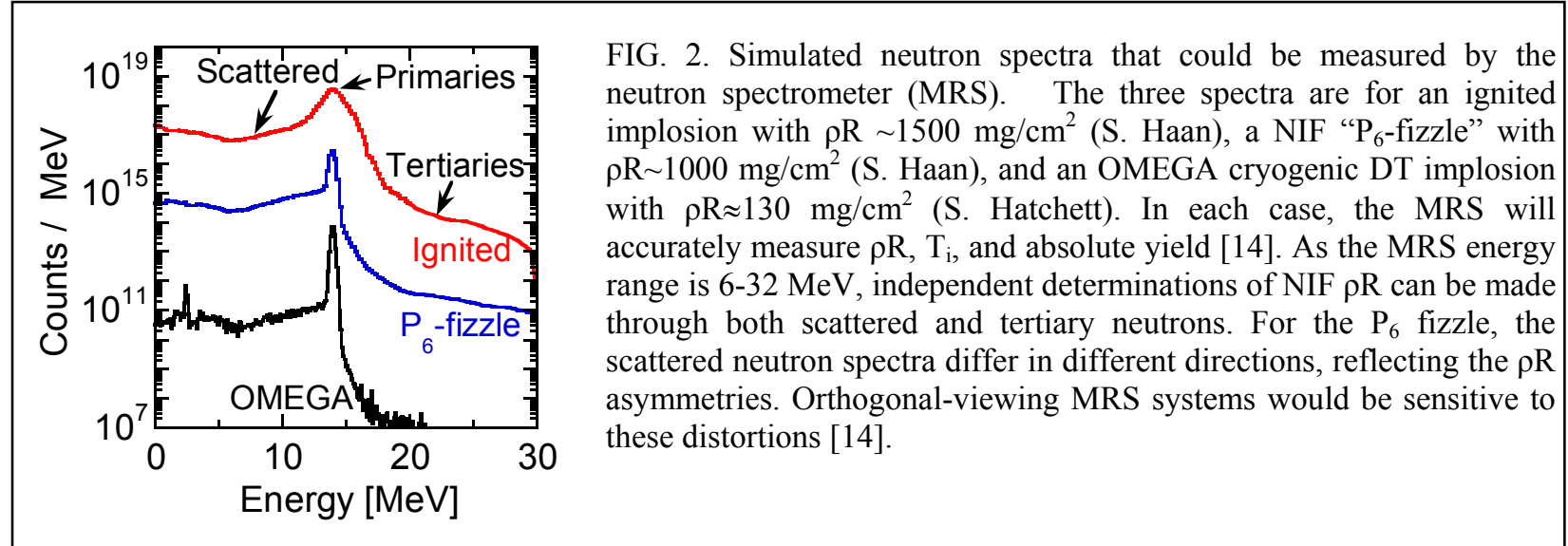

\section{ii. Principles of operation and scientific objectives}

The MRS has three basic components, as indicated in Fig. 1a [14]. The first is a CH (or CD) foil to produce recoil protons (or deuterons) from incident neutrons. The second is a magnet for energy dispersion and for focusing of forward-scattered recoil particles onto a detector plane. This focusing provides a clear mapping between position in the plane and the energy of the proton (or deuteron), and thus the energy of the neutron that scattered it. The third is the detector, which must record the position of each recoil particle and be insensitive to various sources of background; for this we will use CR-39 nuclear track detectors in coincidence mode. Important to the design is the fact that the MRS measures spectra of neutrons between 6 and $32 \mathrm{MeV}$, covering all essential details of the three simulations shown in Fig. 2. For example, from NIF tertiaries [17] a second estimate can be independently made of the fuel $\rho$ R. This can be directly compared to the principal method of $\rho \mathrm{R}$ determination from the scattered primaries. Having such self-consistency checks could prove immensely important for NIF fizzles. In addition, the absolute primary yield and a highly resolved $14.1 \mathrm{MeV}$ primary neutron spectrum can be measured at both OMEGA and the NIF, making possible precise estimates of the ion temperature and (possibly more interestingly) any deviations from a single temperature.

\section{B. Direct drive implosion dynamics and mix at OMEGA}

\section{i. Shock and compression dynamics and mix}

Ignition and high gain in ICF are critically dependent on mitigation of the Rayleigh-Taylor (RT) instability. The RT instability, which is the growth of nonuniformities at a density interface when a lowdensity material accelerates a high-density material, occurs during two distinct intervals in ICF implosions. During the acceleration phase, the low-density ablating plasma accelerates the solid shell 
inwards, and perturbations seeded by energy deposition nonuniformities or initial capsule surface roughness feeds through to the inner fuel-shell surface. During the deceleration phase, shortly before the time of maximum capsule compression, growth of the RT instability at the fuel-shell interface quickly saturates, resulting in small-scale, turbulent eddies that leads to atomic-scale mixing of the fuel and shell. RT growth and the resulting mixing processes disrupt the formation of the hot-spot in the fuel, lowering its temperature and reducing its volume, which may prevent the capsule from igniting. Understanding the nature and timing of RT growth and mix under different conditions is an important step toward mitigating their adverse effects.

To this end, the first temporal measurements of $\mathrm{D}^{3} \mathrm{He}$ protons emitted from ICF implosions of CD-shelled, ${ }^{3} \mathrm{He}$-filled capsules offer new and valuable insights into the dynamics of turbulent mixing induced by saturation of the Rayleigh-Taylor instability [18]. These measurements have demonstrated that bang time is substantially delayed as RT growth saturates to produce mix (Fig. 3). The $75 \pm 30$ ps bang time delay of $\mathrm{CD}$ implosions compared to $\mathrm{D}^{3} \mathrm{He}$-filled, $\mathrm{CH}$ implosions for high initial fill densities is equal to half the burn duration. Reducing $\rho_{0}$ by a factor of five increases the susceptibility of the implosion to mix [19], and does not significantly affect the bang time delay. Continued mixing of the fill gas and shell prolongs nuclear production in $\mathrm{CD}$ capsules even after it is quenched in equivalent $\mathrm{CH}$ capsules. Finally, the relatively small increase in areal density $\rho \mathrm{L}$ measured in $\mathrm{CD}$ compared to $\mathrm{CH}$ capsules, despite the later bang time, suggests that nuclear production is dominated by mixing induced at the tips of RT spikes driven into the core.
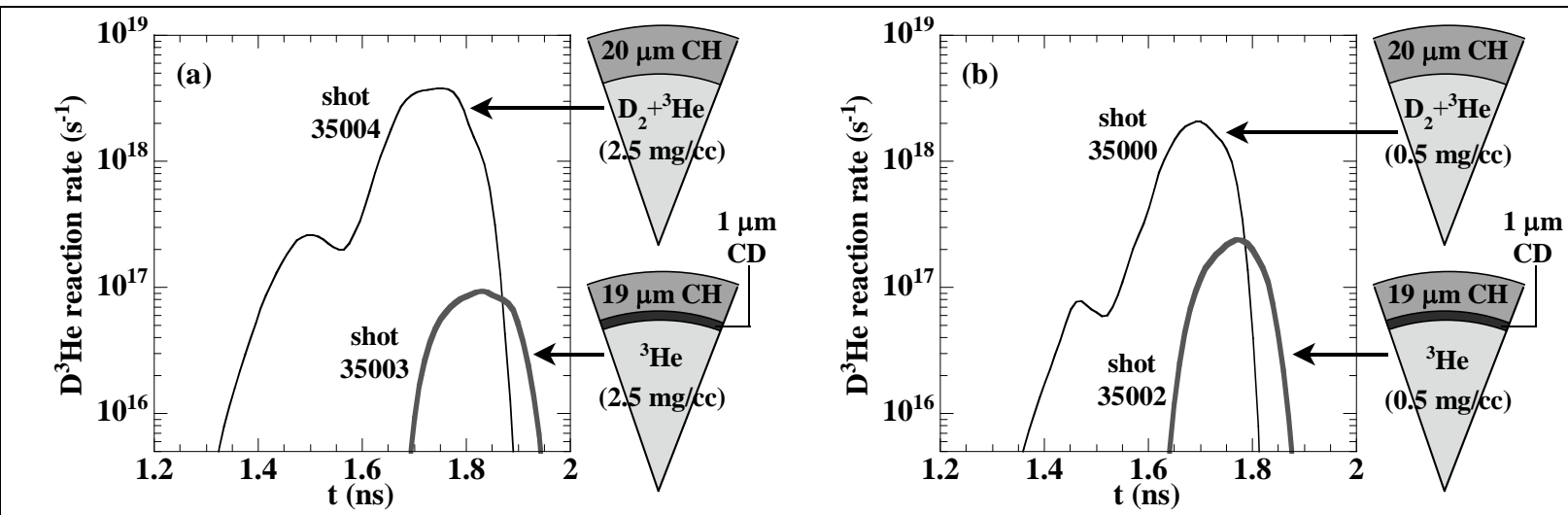

FIG. 3: Measurements of the $\mathrm{D}^{3} \mathrm{He}$ nuclear reaction history from implosions of spherical plastic $(\mathrm{CH})$ shells filled with an equimolar $\mathrm{D}_{2}-{ }^{3} \mathrm{He}$ mixture, and of equivalent $\mathrm{CD}$-layer capsules filled with pure ${ }^{3} \mathrm{He}$. The gaseous fuel was filled to initial densities of (a) $2.5 \mathrm{mg} / \mathrm{cm}^{3}$ and (b) $0.5 \mathrm{mg} / \mathrm{cm}^{3}$. The $\mathrm{CH}$ capsule histories show distinct times of $\mathrm{D}^{3} \mathrm{He}$ nuclear production corresponding to the shock (at $\left.\sim 1.5 \mathrm{~ns}\right)$ and compression $(\sim 1.75 \mathrm{~ns})$ burns. CD capsule implosions require mixing of the fuel and shell on the atomic scale for $\mathrm{D}^{3} \mathrm{He}$ production, and the histories show that no such mix has occurred at shock-bang time. The time necessary for hydro-instabilities to induce fuel-shell mix results in a typical $75 \pm 30$ ps delay in the peak $\mathrm{D}^{3} \mathrm{He}$ reaction rate in $\mathrm{CD}$ capsules compared to equivalent $\mathrm{CH}$ capsules. In addition, nuclear production in $\mathrm{CD}$ implosions continues even after the compression burn ends in $\mathrm{CH}$ capsules, staying well above the typical noise level of $3 \times 10^{15} / \mathrm{s}$ for an additional $50 \mathrm{ps}$.

The higher RT-induced mix susceptibility of capsules filled to lower initial density was observed for a wide range of capsule parameters, as shown in Fig. 4 and as described in Ref. 19. With our colleagues at Los Alamos National Laboratory, the results of these experiments were compared to a multi-fluid interpenetration mix model, where the calculated results also demonstrated increasing mix for lower initial densities, and the experimental observations from $\mathrm{D}_{2}$, DT, and ${ }^{3} \mathrm{He}$ filled implosions could be matched using a single value of the free parameter in the model [20]. 

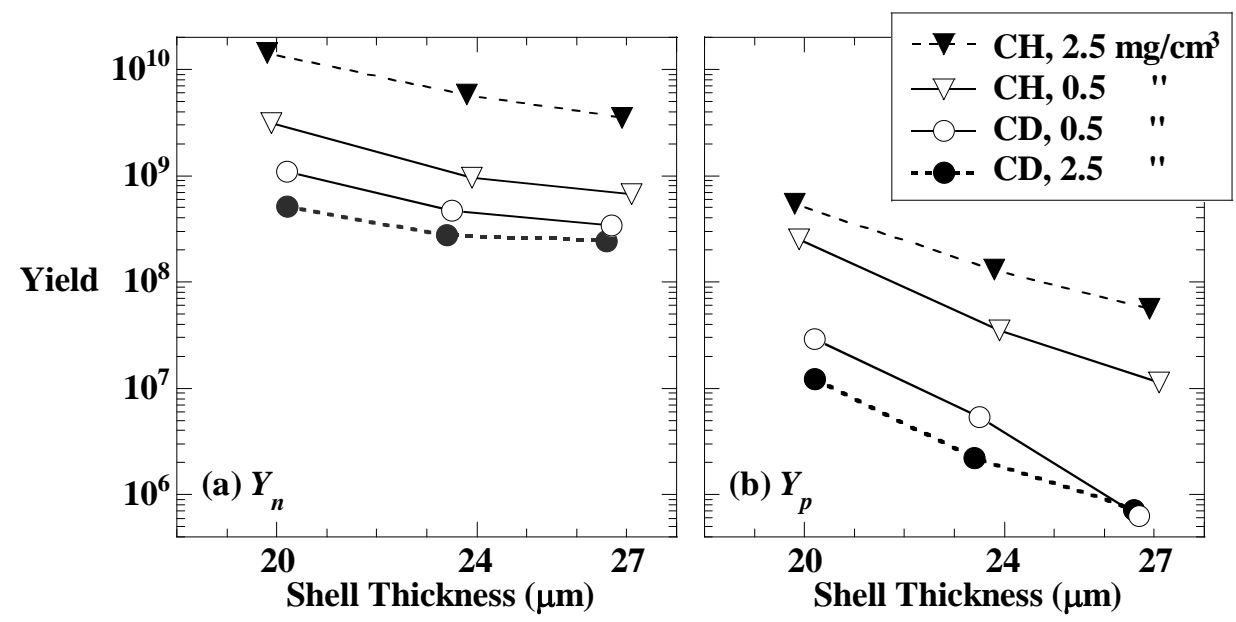

FIG. 4: (a) DD-n and (b) $\mathrm{D}^{3} \mathrm{He}$ yield in $\mathrm{CH}$ (triangles) and CD (circles) capsules with low (open markers) and high (solid markers) $\rho_{0}$ as a function of shell thickness. Capsules with lower $\rho_{0}$ are more susceptible to mix for all shell thicknesses.

\section{ii. $\quad \rho R$ at shock-coalescence time}

Accurate predictions concerning the propagation of convergent shocks are essential for ignition and high gain in ICF. Current ICF ignition designs include a sequence of up to four convergent shocks which must be precisely timed to coalesce at the inner shell surface so as to obtain maximal shell compression, a necessity for high fusion gain. All shocks formed after the first must propagate through already-shocked material, which introduces uncertainty into the shock speed and strength. Thorough understanding of shock speeds in cold and heated material, and in planar and convergent geometries, will be vital for satisfactory ICF implosion performance.

Nuclear production induced by the collapse of strong, spherically convergent shocks was observed using temporal and spectral measurements of products from two distinct nuclear reactions (Fig. 5) [21]. The dual nuclear observations create a comprehensive description of the state of the implosion at shock collapse time, immediately before the onset of the deceleration phase, and revealed numerous differences from predictions made by 1D hydrodynamic simulations. Measurements demonstrated that shock collapse occurs $200-350$ ps earlier, that nuclear production is 8 to 30 times lower, and that capsule compression as measured by the areal density $\rho \mathrm{R}$ is only half of what simulations predict (Fig. 6). Although adjustments to the simulation flux limiter can be made to match the timing, no value of the flux limiter can match the shock timing, yield, and $\rho \mathrm{R}$ simultaneously. Measuring both DD and $\mathrm{D}^{3} \mathrm{He}$ nuclear products allowed a shock temperature near $6 \mathrm{keV}$ to be inferred, and acts as a powerful constraint and verification of data reliability. Given the importance of shock timing and heating to the success of ignition in ICF, it is worthwhile to reexamine the treatment of shocks in current hydrodynamic codes; the constraints imposed by this compelling set of dual nuclear shock burn measurements allows efficient and insightful alterations to be selectively made in ICF simulations at a level hitherto unavailable. 

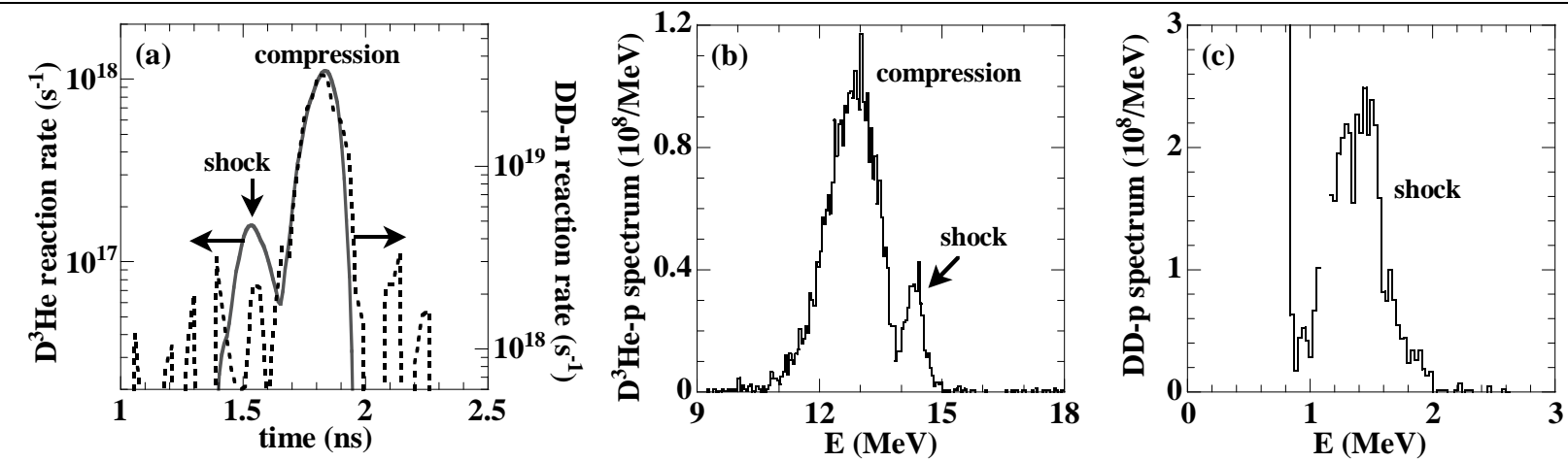

FIG. 5.: Shock $\rho \mathrm{R}$ values for $18 \mathrm{~atm}$ and $3.6 \mathrm{~atm} \mathrm{D}^{3} \mathrm{He}$ fills of capsules with various shell thickness. The experimental $\rho \mathrm{R}_{\mathrm{sh}}$ is inferred from the downshift of (a) $14.7 \mathrm{MeV} \mathrm{D}^{3} \mathrm{He}$ protons and (b) $3 \mathrm{MeV}$ DD-protons from their birth energy. Markers show mean and standard error. (c) The simulated $\rho \mathrm{R}$ is the $\rho \mathrm{R}$ of the implosion weighted by the $\mathrm{D}^{3} \mathrm{He}$ reaction rate over the shock burn.

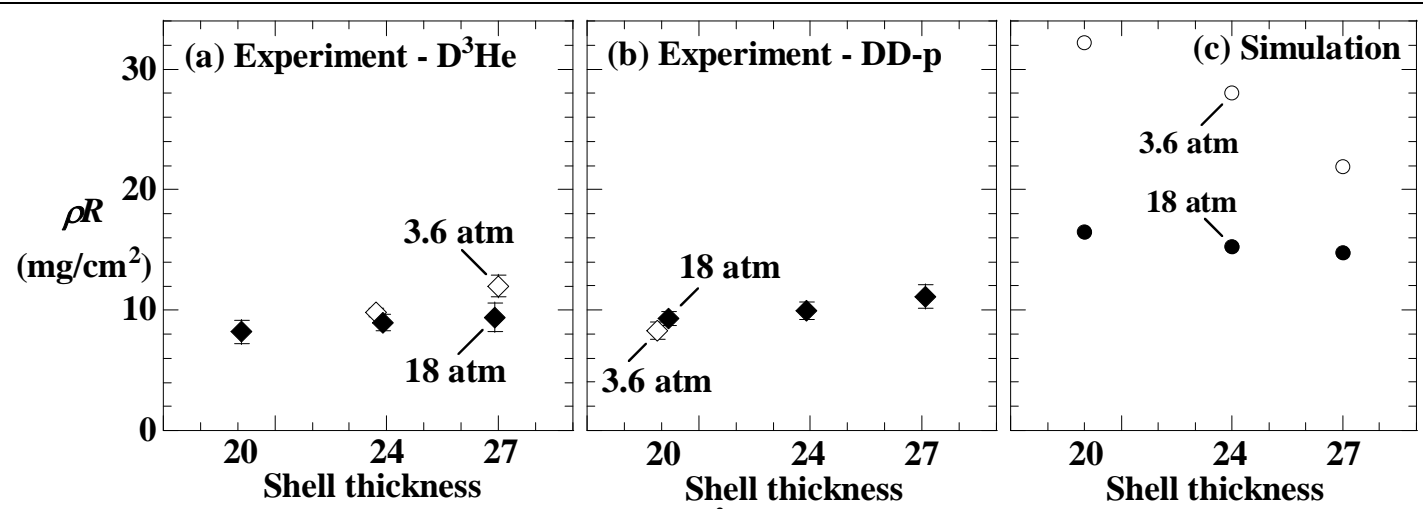

FIG. 6. Shock $\rho \mathrm{R}$ values for $18 \mathrm{~atm}$ and $3.6 \mathrm{~atm} \mathrm{D}^{3} \mathrm{He}$ fills of capsules with various shell thickness. The experimental $\rho R_{\text {sh }}$ is inferred from the downshift of (a) $14.7 \mathrm{MeV} \mathrm{D}{ }^{3} \mathrm{He}$ protons and (b) $3 \mathrm{MeV}$ DD-protons from their birth energy. Markers show mean and standard error. (c) The simulated $\rho R$ is the $\rho R$ of the implosion weighted by the $\mathrm{D}^{3} \mathrm{He}$ reaction rate over the shock burn.

\section{iii. $\quad \mathrm{DD}$ and $\mathrm{D}^{3} \mathrm{He}$ burn rates for different mixtures of $\mathrm{D}$ and ${ }^{3} \mathrm{He}$}

Direct drive implosions of targets filled with different mixtures of $\mathrm{D}_{2}$ and ${ }^{3} \mathrm{He}$ gas on the OMEGA laser system have shown an unexpected scaling of experimental nuclear yields [22]. At temperatures above a few $\mathrm{eV}, \mathrm{D}_{2}$ and ${ }^{3} \mathrm{He}$ gasses are fully ionized; and hydrodynamically-equivalent fuels with different ratios of $\mathrm{D}_{2}$ and ${ }^{3} \mathrm{He}$ can be chosen to have the same mass density, total particle density and equation of state. Implosions with a 50-50 mixture of $\mathrm{D}:{ }^{3} \mathrm{He}$ by atom consistently result in measured nuclear yields half of that anticipated by scaling from measured yields of implosions with pure $\mathrm{D}_{2}$ and nearly pure ${ }^{3} \mathrm{He}$ (Fig. 7). This observation is seen over a wide range of experimental configurations, including targets with a variety of shell thicknesses and fill pressures, simultaneously for two different nuclear yields (D-D and D- ${ }^{3} \mathrm{He}$ ), as well as for shock and compression yields. A number of possible mechanisms to cause the scaling are considered, but no dominant mechanism has been identified. 

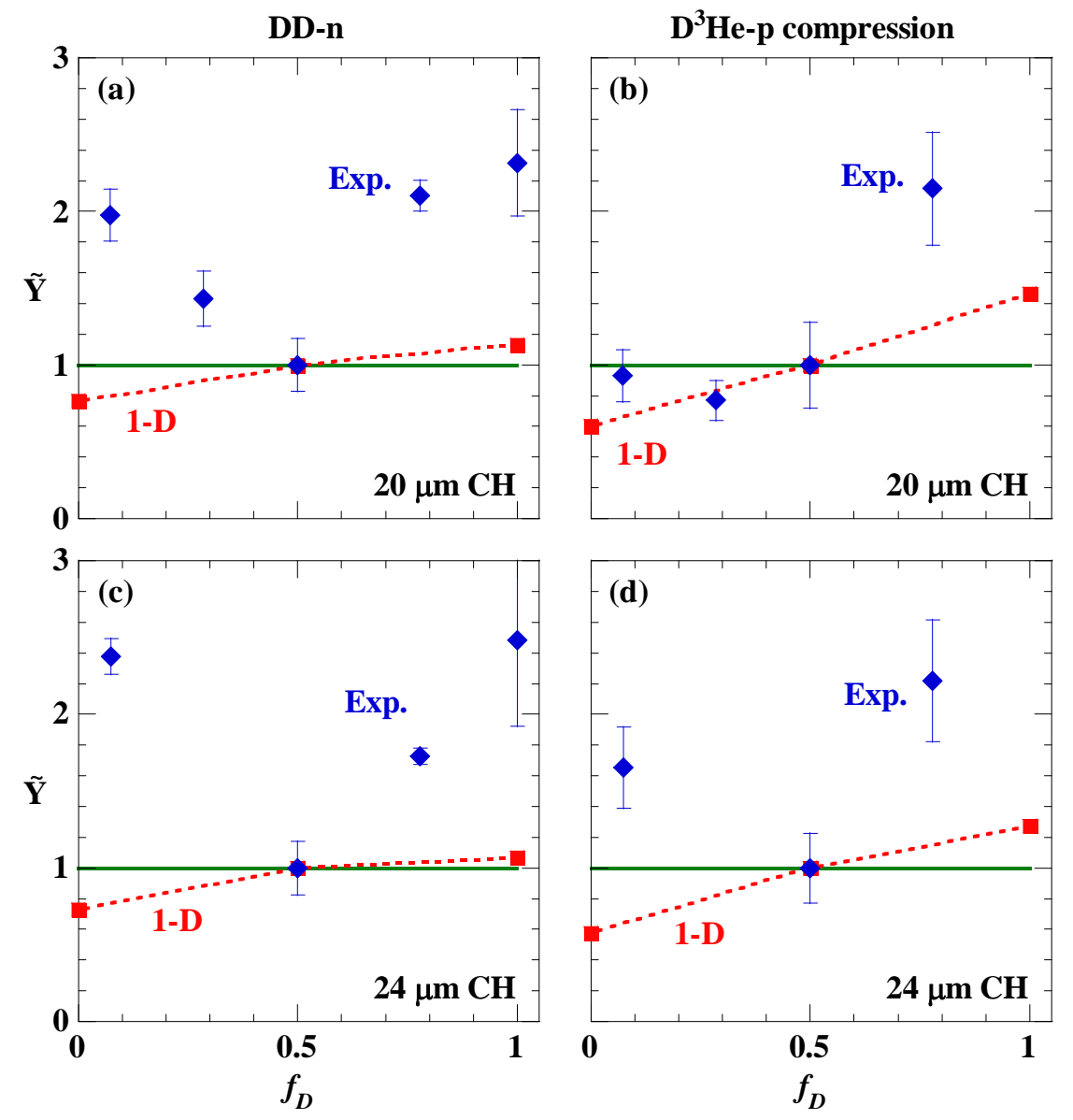

FIG. 7: Scaled DD-n and $D^{3} \mathrm{He}$ compression yields from implosions of capsules with 20 or $24 \mu \mathrm{m}$ thick shells, filled with gaseous $\mathrm{D}_{2}$ and ${ }^{3} \mathrm{He}$ mixtures, as a function of deuterium fraction by atom $\left(f_{D}\right)$ in the fill gas. (a) DD-n, $20 \mu \mathrm{m}$; (b) $\mathrm{D}^{3} \mathrm{He}, 20 \mu \mathrm{m}$; (c) DD-n, $24 \mu \mathrm{m}$; (d) $\mathrm{D}^{3} \mathrm{He}, 24 \mu \mathrm{m}$. All yields have been scaled to the expected fill composition as described in Reference [22], and normalized to the yields at $f_{D}=0.5$. True hydro-equivalent implosions would scale to a value of one (solid green line). 1-D simulations with LILAC (red squares, dotted) deviate slightly from hydroequivalence, but not nearly as much as experimental measurements (blue diamonds). Diamonds are the average yield and standard deviation from similar capsules. The $20 \mu \mathrm{m}$ plots show data reduced from a total of 42 shots, and the $24 \mu \mathrm{m}$ plots show data reduced from a total of 24 shots. 


\section{Imaging nuclear burn with implosion fusion protons}

Measured burn images and burn profiles provide compelling insight into implosion dynamics, including the combined effects of mix, hydro efficiency, and electron and radiation transport. To that end, we developed a method of imaging with $\mathrm{D}^{3} \mathrm{He}$ protons produced in implosions of capsules filled with $\mathrm{D}^{3} \mathrm{He}$ fuel, using multiple imaging cameras from up to three directions simultaneously for quantitative, 3$\mathrm{D}$ spatial measurements of the fusion burn region in direct-drive implosions on OMEGA. Images from three orthogonal penumbral imaging cameras are processed with special algorithms [23-35] to find either the radial profile of $\mathrm{D}^{3} \mathrm{He}$ reactions per unit volume, when burn is spherically symmetric, or the surface brightness of burn regions with arbitrary asymmetric structure.

\section{i. Radial burn-region profiles and sizes of different implosion types}

Figure 8a shows a sample radial profile of burn for a symmetric OMEGA implosion, while Fig. 8b shows examples of how the size of the burn region varies for different laser energies and shell types. The burn regions of imploded thin-glass-shell capsules get larger with increasing laser energies; the burn regions of thick-plastic-shell capsules are, not surprisingly, significantly smaller than those of glass-shell capsules imploded with the same laser energy. Figure 8c shows that decreasing fill pressure can lead to diminished burn region size, even though shell convergence (as indicated by $\rho \mathrm{R}$ ) does not notably increase. This is supported by our previous finding [26] from studies of similar DT implosions that a reduction of pressure did not lead to much increase in radial convergence, in contrast to predictions of 1D codes, and was probably an indication of increased fuel-shell mix; the reduction in burn region size at lower pressures seen here may be another sign that mix is more extensive, cooling more of the outer fuel region.

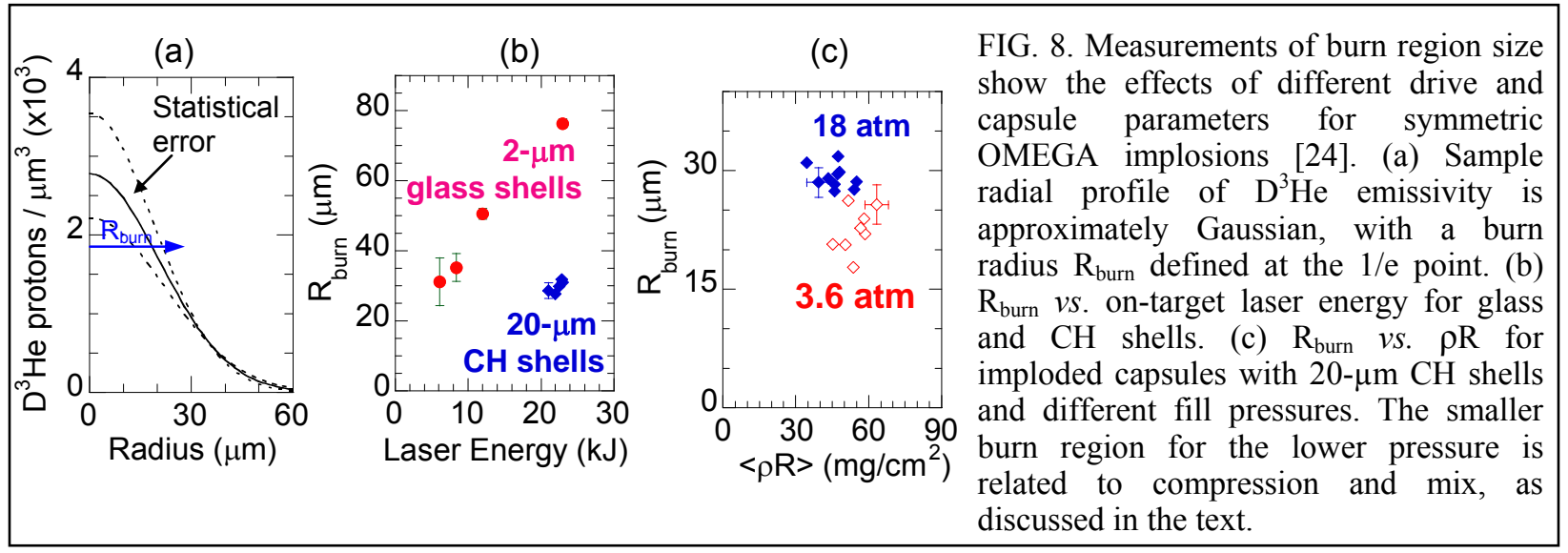

\section{ii. 3-D burn asymmetries resulting from drive asymmetry and capsule shimming}

Figure 9 shows an example of how (intentionally) asymmetric laser drive results in an asymmetric burn region. Similar results for different types and amplitudes of drive asymmetry, and for capsule shell asymmetry, show clear correlations between drive and capsule conditions and burn asymmetry. Spatial distributions of drive, capsule shell thickness, and burn will be represented here as sums of Legendre polynomials $\sum_{\ell} A_{\ell} P_{\ell}(\cos \theta)$. We are interested here in low mode numbers, and will talk primarily about $P_{2}$ asymmetries that are quantified by the ratio $A_{2} / A_{0}$. The effects of drive asymmetry on spherical capsules were studied in a series of experiments using $17-\mu \mathrm{m}$-thick $\mathrm{CH}$ shells, with $860-\mu \mathrm{m}$ outer 
diameters, filled with 20 atm of $\mathrm{D}^{3} \mathrm{He}$. The laser drive was provided by OMEGA's 60 beams in a 1-ns square, $18 \mathrm{~kJ}$ pulse, but the intensities of individual beams were adjusted to produce nearly pure $P_{2}$ distortions with several values of the ratio $\left(A_{2} / A_{0}\right)_{\text {drive }}$ spanning the range from -0.36 to +0.17 . For each case, the ratio $\left(A_{2} / A_{0}\right)_{\text {drive }}$ describing the burn distribution was determined from the imaging data. The images shown in Fig. 9 were recorded from the direction of a pole and from two nearly orthogonal directions for the case $\left(A_{2} / A_{0}\right)_{\text {drive }}=-0.36$; they show that the burn region was elongated precisely along the symmetry axis,

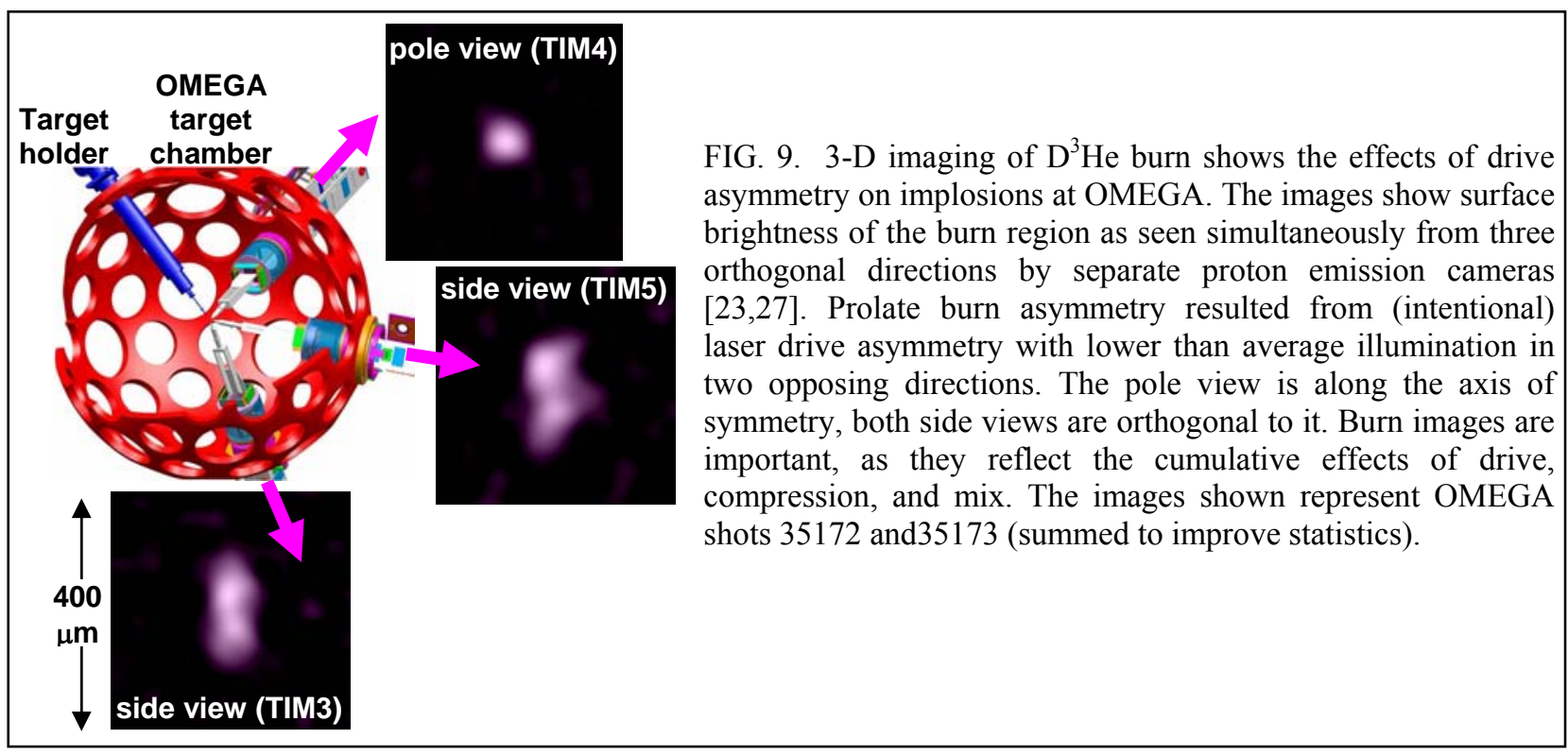

The effect of low-mode variations in capsule shell thickness was studied in a separate experiment using 860- $\mu \mathrm{m}$ diameter, 20- $\mu \mathrm{m}$-thick $\mathrm{CH}$ shells, filled with $18 \mathrm{~atm}$ of $\mathrm{D}^{3} \mathrm{He}$, and symmetric drive in a 1ns-square, $22 \mathrm{~kJ}$ pulse. A symmetric capsule was used for reference, and proton-emission images of the spatial distributions of $\mathrm{D}^{3} \mathrm{He}$ reactions indicated spherical symmetry. To see the effects of shimming, we used a capsule that was essentially identical except that the shell thickness was $19.1 \mu \mathrm{m}$ at the equator and $21 \mu \mathrm{m}$ at the pole $\left[\left(A_{2} / A_{0}\right)_{\text {shell }}=0.07\right]$. Some results of that experiment are shown in Fig. 10. The protonemission images indicate that the spatial distribution of fusion reactions was prolate, with symmetry axis aligned with that of the shimmed target capsule; there was less compression of the hot fuel where the shell was thicker. This was precisely the effect expected, and was repeated in a second experiment. In addition to proton-emission images, $\mathrm{x}$-ray images were recorded at bang time. The image shown in Fig. 10. demonstrates that the inner shell surface was also prolate, with the same axis of symmetry as the emission image and a slightly larger size.

The asymmetries of all the burn regions in these experiments can be quantified by measuring $\left(A_{2} / A_{0}\right)_{\text {burn }}$ from the images [25]; these are plotted in Fig. 11. Figure 12 shows both the $\mathrm{D}^{3} \mathrm{He}$ and DD yields. Although the two series of experiments utilized slightly different capsule and drive conditions, as discussed above, they were quite similar and allow us to do some general comparisons. From Figs. 11 and 12 , it can be seen that relatively small deviations of either drive or shell thickness from spherical symmetry leads to significant falloff of fusion yields in conjunction with a loss of burn symmetry.

From Fig. 11, it can be seen that both drive asymmetry and shell asymmetry lead to burn asymmetry in systematic and expected ways. This implies that it should be possible to compensate for drive asymmetry with an appropriate amount of intentional shell asymmetry (shell "shimming" [28]). From the slopes of the two plots, which differ by a factor of about -2.5 , we might predict that implosion symmetry would be approximately maintained if $\left(A_{2} / A_{0}\right)_{\text {shell }} \approx 0.4\left(A_{2} / A_{0}\right)_{\text {drive. }}$. We have shown that the trends seen in Fig. 11 are understandable as logical consequences of the "rocket equation" description of shell acceleration due to radiation-induced shell ablation [1], and that an analytic model [25] can be used to 
predict the amount of shell shimming that would result in greatly reduced implosion asymmetry in situations where drive asymmetry is unavoidable (such as "polar direct drive" [29] in anticipated experiments at the National Ignition Facility).
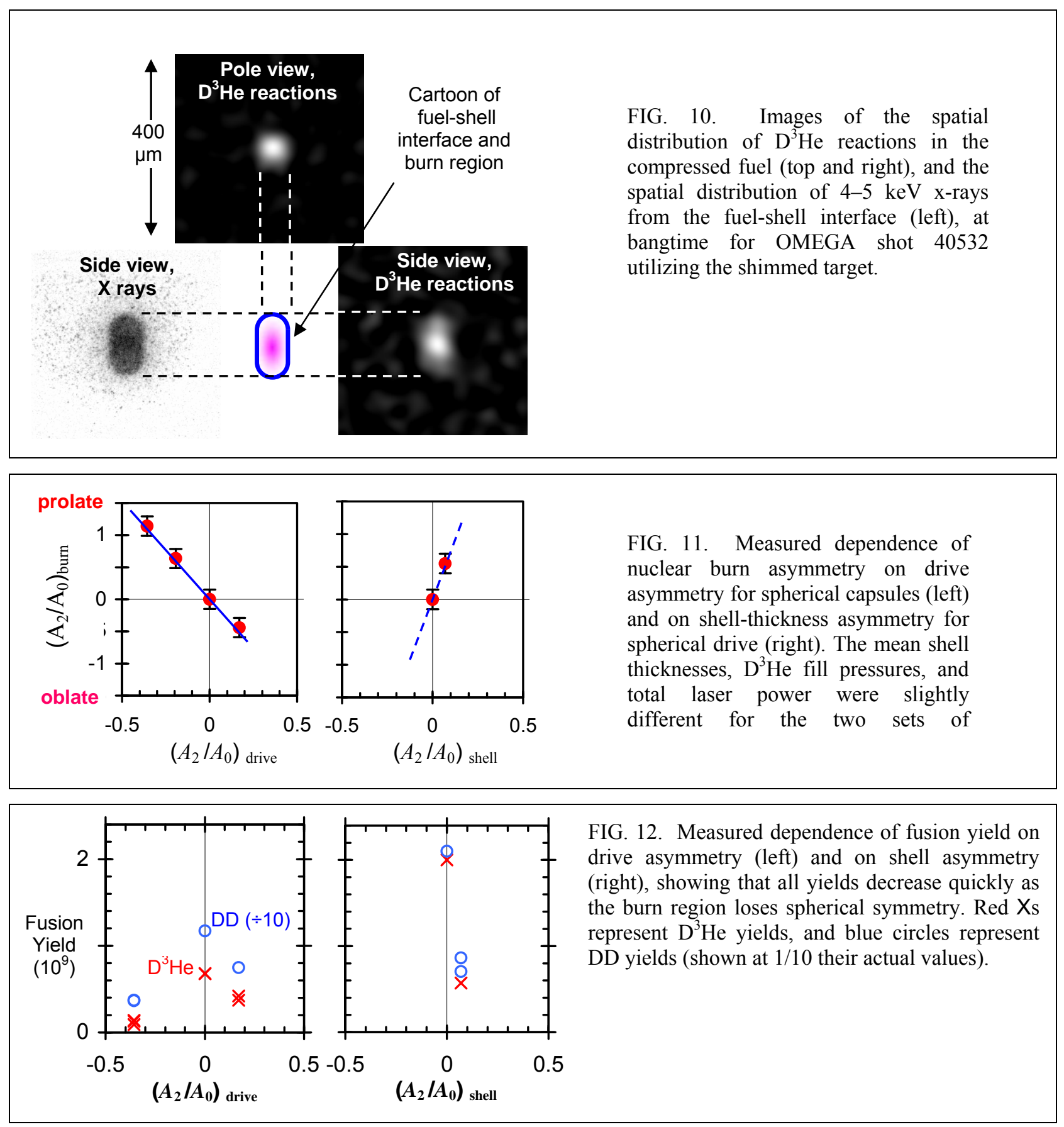

\section{Indirect drive studies at OMEGA}

Several experimental campaigns involving the use of MIT diagnostics in studying indirect-drive experiments organized at OMEGA by scientists at Lawrence Livermore National Laboratory. These campaigns have led to active, ongoing discussions with LLNL about future work, and we have demonstrated the feasibility of making relevant measurements, but so far shots have not been available to us. 


\section{E. Graduate and undergraduate student training, education and research}

The MIT group has outstanding graduate and undergraduate students training in ICF and HEDP. They are involved in a wide range of projects from experimental to simulation to theory. The graduate students are deeply engaged in every aspect of our research program, and spend considerable time at LLE working on experiments and working with our collaborators from LLE and from the National Labs. They report their results at the major conferences (DPP, Anomalous, IFSA, HTPD), at National Laboratory workshops and seminars, and at seminars at MIT and LLE, and they write up their work for submission to refereed physics journals. Each graduate student typically has three major first-author publications as well as co-authorship on several (typically 5-7) other major publications by the completion of their thesis. During the contract period we had the five graduate students shown on the chart in Sec. IV. Graduate student Ryan Rygg was awarded $1^{\text {st }}$ Place Excellence Awards for his Graduate Research at NNSA symposia, and he finished his degree laser year. He has worked with us a postdoc since then, and we expect that next year he will work at one of the national laboratories. His $\mathrm{PhD}$ thesis has been nominated for the Marshall Rosenbluth outstanding thesis award.

We have found that the undergraduates are also quite eager to participate and to learn about ICF. The MIT Fusion Product Source gives them hands-on experience with many of the techniques we are using at, or developing for, OMEGA and the NIF. At six undergraduates worked in our group during the contract period (see Sec. IV). Each had a project for which he or she had primary responsibility, and one (A. McGlaughlin) is currently writing a senior thesis based on his project.

\section{SCHEDULE AND COMPARISON OF ACCOMPLISHMENTS WITH OBJECTIVES}

Progress is on schedule, with approximately $1 / 3$ of the tasks complete after the first of three years of grant funding. Here is a breakdown of the items listed in the Statement of Work, with estimates of progress:

\begin{tabular}{|c|c|c|c|}
\hline Task & $\%$ complete & Notes & $\begin{array}{l}\text { If not complete, predicted } \\
\text { completion date }\end{array}$ \\
\hline A1 & $\sim 50$ & Assembly and alignment complete in July 2007 & July 2007 \\
\hline A2 & - & $\begin{array}{l}\text { Calibration and characterization will take place } \\
\text { in fall } 2007\end{array}$ & January 2008 \\
\hline A3 & - & Finish the MRS qualification & April 2008 \\
\hline A4 & - & $\begin{array}{l}\text { Produce reliable } \rho \text { R data for cryogenic DT } \\
\text { implosions }\end{array}$ & July 2008 \\
\hline B1 & 100 & & - \\
\hline B2 & 100 & & - \\
\hline B3 & - & & February 2009 \\
\hline B4 & 33 & & February 2009 \\
\hline $\mathrm{C} 1$ & 50 & & February 2009 \\
\hline $\mathrm{C} 2$ & 100 & & - \\
\hline $\mathrm{C} 3$ & 100 & & - \\
\hline$\overline{\mathrm{D} 1}$ & - & $\begin{array}{l}\text { As described in Sec. I-D, indirect drive studies } \\
\text { are still in the planning phase }\end{array}$ & February 2009 \\
\hline $\mathrm{D} 2$ & - & & “ \\
\hline D3 & - & & “" \\
\hline E1 & 33 & Successful ongoing process. & “" \\
\hline E2 & 33 & "6 & “" \\
\hline E3 & 33 & "“ & “" \\
\hline
\end{tabular}




\section{COST STATUS}

$\begin{array}{lrr}\text { Approved Budget }(4 / 15 / 06-4 / 15 / 07): & \$ 450,000.00 \\ \text { Expenses } & (4 / 15 / 06-4 / 15 / 07): & 448,090.53\end{array}$

Balance:

$1,909.47$

\section{TEAM MEMBERS}

\begin{tabular}{|l|l|l|l|}
\hline $\begin{array}{l}\text { MIT } \\
\text { Scientists }\end{array}$ & Technical Staff & Graduate Students & Undergraduate Students \\
\hline Dr. Richard Petrasso & Jocelyn Schaeffer & Cliff Chen & Siddarth Sundar \\
\hline Dr. Chikang Li & Randy Leiter & J. Ryan Rygo & Jeffrey Perez \\
\hline Dr. Fredrick Seguin & Sean McDuffee & Daniel Casey & Sohrab Virk \\
\hline Dr. Johan Frenje & Irina Cashen & Mario Manuel & Jeremy Chang \\
\hline & & & Jeremy Jacox \\
\hline & & & Andy McGlaughlin \\
\hline
\end{tabular}

* Received his PhD in October 2006, and since then has been a postdoc in our group.

\section{GROUP PUBLICATIONS DURING THE PERIOD OF THE GRANT}

Note that many of our papers are available on our Internet site at the URL

"http://psfcwww2.psfc.mit.edu/physics_research/hedp/Papers/Papers.html".

In preparation for submission:

1. J.A. Frenje et al., "A magnetic recoil spectrometer (MRS) for absolute measurements of the neutron spectrum from which $\rho \mathrm{R}$, Ti and yield can be inferred for cryogenic DT implosions at OMEGA and the NIF".

2. F. H. Séguin et al., "Proton radiography options for OMEGA EP".

3. J.A. Frenje et al., "Diagnosing $\rho \mathrm{R}$ and $\rho \mathrm{R}$ modulations of the ablator for failed NIF implosions using charged-particle spectrometry".

4. F. H. Séguin et al., "Angular distributions of areal density in ICF implosions with asymmetric drive".

5. J. R. Rygg et al., "Monoenergetic proton radiography of cone-in-shell implosions".

6. R.D. Petrasso et al., "Monoenergetic proton radiography of direct-drive capsule implosions".

7. F. H. Séguin et al., "Electromagnetic fields outside imploded ICF capsules".

8. C. K. Li and R.D. Petrasso, "Effects of Fast Electron Energy Loss on Interactions in Plasmas".

9. F. H. Seguin et al., "Target shimming for control of ICF implosion symmetry".

10. J.R. Rygg et al., "Observations of the collapse of asymmetrically-driven convergent shocks".

11. J.A. Frenje et al., "Diagnosing cryogenic DT implosions at OMEGA using charged-particle spectrometry".

12. D.T. Casey et al., "Background characterization and reduction for the Magnetic Recoil Spectrometer (MRS) at OMEGA and the NIF". 


\section{Submitted:}

13. J.R. Rygg, J.A. Frenje, C. K. Li, F. H. Séguin, R. D. Petrasso, J. A. Delettrez, D. D. Meyerhofer, T.C. Sangster, and C. Stoeckl, "Dual nuclear product observations of shock collapse in inertial confinement fusion", submitted to Phys. Rev. Lett. (2007).

14. C. K. Li, F. H. Séguin, R. P. J. Town, R. D. Petrasso, J. A. Frenje, J. P. Knauer, O. L. Landen, J. R. Rygg, V. A. Smalyuk, "Observation of Megagauss Field Topology Changes due to Magnetic Reconnection in Laser-Produced Plasmas", submitted to Phys. Rev. Lett (2007).

\section{Accepted:}

15. C. K. Li, F. H. Séguin, J. A. Frenje, J. R. Rygg, R. D. Petrasso, R. P. J. Town, P. A. Amendt, S. P. Hatchett, O. L. Landen, A. J. Mackinnon, P. K. Patel, M. Tabak, J. P. Knauer, T. C. Sangster, and V. A. Smalyuk, "Observation of the Decay Dynamics and Instabilities of Megagauss Magnetic Field Structures in Laser-Produced Plasmas", accepted for publication in Phys. Rev. Lett. (2007).

16. J. R. Rygg, J. A. Frenje, C. K. Li, F. H. Seguin, R. D. Petrasso, V. Yu Glebov, D. D. Meyerhofer, T. C. Sangster, and C. Stoeckl, "Time-dependent measurements of mix in inertial confinement fusion", accepted for publication in Phys. Rev. Lett. (2007).

17. C. Chen, C. K. Li, and R.D. Petrasso, "Comparison of solid and plasma linear energy deposition for electron preheat and fast ignition scenarios", accepted in J. Applied Physics (2007).

\section{Published:}

18. J. R. Rygg, J. A. Frenje, C. K. Li, F. H. Seguin, R. D. Petrasso, J. A. Delettrez, V. Yu. Glebov, V. N. Goncharov, D. D. Meyerhofer, P. B. Radha, S. P. Regan, and T. C. Sangster, "Nuclear measurements of fuel-shell mix in inertial confinement fusion implosions at OMEGA", Phys. Plasmas 14, 056306 (2007).

19. C. D. Zhou, W. Theobald, R. Betti, P.B. Radha, V.A. Smalyuk, D. Shvarts, V. Yu. Glebov, C. Stoeckl, K.S. Anderson, D.D. Meyerhofer, T.C. Sangster, C.K. Li, R.D. Petrasso, J.A. Frenje, and F.H. Seguin, "High- $\rho$ R Implosions for Fast-Ignition Fuel Assembly", Phys. Rev. Lett. 98,025004 (2007).

20. V.A. Smalyuk, R. Betti, J.A. Delettrez, V. Yu. Glebov, V. N. Goncharov, D.Y. Li, D.D. Meyerhofer, S.P. Regan, S. Roberts, T.C. Sangster, C. Stoeckl, W. Seka, J.A. Frenje, C.K. Li, and R.D. Petrasso, "Experimental studies of direct-drive, low-intensity, low-adiabat spherical implosions on OMEGA", Phys. Plasmas 14, 056306 (2007).

21. T.C. Sangster, R. Betti, R.S. Craxton, J.A. Delettrez, D.H. Edgell, L.M. Elasky, V.Yu. Glebov, V.N. Goncharov, D.R. Harding, D. Jacobs-Perkins, R. Janezic, R.L. Keck, J.P. Knauer, S.J. Loucks, L.D. Lund, F.J. Marshall, R.L.McCrory, P.W. McKenty, D.D. Meyerhofer, P.B. Radha, S.P. Regan, W. Seka, W.T. Shmayda, S. Skupsky, V.A. Smalyuk, J.M. Soures, C. Stoeckl, B Yaakobi, J.D. Moody, J.A. Atherton, B.D. MacGowan, J.D. Kilkenny, T.P. Bernat, J.A. Frenje, C.K. Li, R.D. Petrasso, F.H. Seguin and D.S. Montgomery, "Cryogenic DT and D2 Targets for inertial confinement fusion," Phys. Plasmas 14, 058101 (2007.)

22. G. Kyrala, D.C. Wilson, J.F. Benage, M. Gunderson, K. Klare, W. Garbett, S. James, V. Glebov, B. Yaakobi, J. A. Frenje, and R. Petrasso, "Effect of higher z dopants on implosion dynamics: X-ray spectroscopy," High Energy Density Physics (2007), doi:10.1016/j.hedp.2007.02.018.

23. C. K. Li, F.H. Seguin, J.A. Frenje, J. R. Rygg, R.D. Petrasso, R.P.J. Town, P.A. Amendt, S.P. Hatchett, O.L. Landen, A.J. Mackinnon, and P.K. Patel, "Measuring E and B fields in Laser-Produced Plasmas with Monoenergetic Proton Radiography", Phys. Rev. Lett. 97135003 (2006).

24. F. H. Seguin, J. L. DeCiantis, J. A. Frenje, C. K. Li, J. R. Rygg, C. D. Chen, R. D. Petrasso, J. A. Delettrez, S. P. Regan, V. A. Smalyuk, V. Yu. Glebov, J. P. Knauer, F. J. Marshall, D. D. Meyerhofer, S. Roberts, T. C. Sangster, C. Stoeckl, K. Mikaelian, H. S. Park, H. F. Robey, and R. E. 
Tipton, "Measured dependence of nuclear burn region size on implosion parameters in inertial confinement fusion experiments", Phys. Plasmas 13 , 082704 (2006).

25. C. K. Li and R. D. Petrasso, "Energy deposition of MeV electrons in compressed targets of fastignition inertial confinement fusion", Phys. Plasmas 13 , 056314 (2006).

26. J. R. Rygg, J. A. Frenje, C. K. Li, F. H. Séguin, R. D. Petrasso, J. A. Delettrez, V. Yu Glebov, V. N. Goncharov, D. D. Meyerhofer, S. P. Regan, T. C. Sangster, and C. Stoeckl, "Tests of the

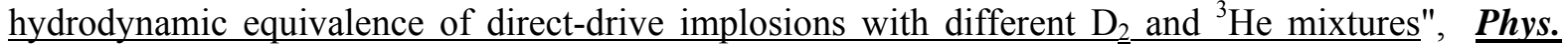
Plasmas 13 , 052702 (2006).

27. V. Yu. Glebov, D. D. Meyerhofer, T. C. Sangster, C. Stoeckl, S. Roberts, C. A. Barrera, J. R. Celeste, C. J. Cerjan, L. S. Dauffy, D. C. Eder, R. L. Griffith, S. W. Haan, B. A. Hammel, S. P. Hatchett, N. Izumi, J. R. Kimbrough, J. A. Koch, O. L. Landen, R. A. Lerche, B. J. MacGowan, M. J. Moran, E. W. Ng, T. W. Phillips, P. M. Song, R. Tommasini, B. K. Young, S. E. Caldwell, G. P. Grim, S. C. Evans, J. M. Mack, T. J. Sedillo, M. D. Wilke, D. C. Wilson, C. S. Young, J. L. Bourgade, L. Disdier, M. Houry, I. Lantuejoul, O. Landoas, G. A. Chandler, G. W. Cooper, R. J. Leeper, R. E. Olson, C. L. Ruiz, M. A. Sweeney, S. P. Padalino, C. Horsfield, B. A. Davis, D. Casey, J. A. Frenje, C. K. Li, R. D. Petrasso, and F. H. Séguin, "Development of nuclear diagnostics for the National Ignition Facility (invited)", Rev. Sci. Instrum. 77, 10E715 (2006).

28. R. Betti, K. Anderson, T.R. Boehly, T.J.B. Collins, R.S. Craxton, J.A. Delettrez, D.H. Edgell, R.Epstein, V. Yu Glebov, V.N. Goncharov, D.R. Harding, R.L. Keck, J.H. Kelly, J.P. Knauer, S.J. Loucks, J.A. Marozas, F.J. Marshall, A.V. Maximov, D.N. Maywar, R.L. McCrory, P.W. McKenty, D.D. Meyerhofer, J. Myatt, P.B. Radha, S.P. Regan, C. Ren, T.C. Sangster, W. Seka, S. Skupsky, A.A. Solodov, V.A. Smalyuk, J.M. Soures, C. Stoeck, W. Theobald, B Yaakobi, C. Zhou, J.D. Zuegal, J. Frenje, C.K. Li, R.D. Petrasso, and F.H. Seguin "Progress in hydrodynamics theory and experiments for direct-drive and fast ignition inertial confinement fusion," Plasma Phys. Control Fusion 48, B153 (2006).

29. C. K. Li and R. D. Petrasso, "Stopping, straggling, and blooming of directed energetic electrons in hydrogenic and arbitrary-Z plasmas", Phys. Rev. E 73, 016402 (2006).

30. C. K. Li, F. H. Séguin, J. A. Frenje, J. R. Rygg, R. D. Petrasso, R. P. J. Town, P. A. Amendt, S. P. Hatchett, O. L. Landen, A. J. Mackinnon, P. K. Patel, V. A. Smalyuk, J. P. Knauer, T. C. Sangster, and C. Stoeckl, "Monoenergetic proton backlighter for measuring E and B fields and radiographing implosions and high-energy density plasmas (invited)", Rev. Sci. Instrum. 77, 10E725 (2006).

31. D. C. Wilson, R. L. Singleton, Jr., J. P. Grondalski, N. M. Hoffman, A. Nobile, Jr., F. H. Séguin, J. A. Frenje, C. K. Li, and R. D. Petrasso, "Diagnosing ablator burn through in ignition capsules using $\underline{\mathrm{D}}_{2}{ }^{3} \mathrm{He}$ gas filled surrogates", Rev. Sci. Instrum. 77, 10E711 (2006).

32. V. Tang, J. Liptac, R. R. Parker, P. T. Bonoli, C. L. Fiore, R. S. Granetz, J. H. Irby, Y. Lin, S. J. Wukitch, and The Alcator C-Mod Team, J. A. Frenje, R. Leiter, S.C. McDuffee, R. D. Petrasso, "Compact multichannel neutral particle analyzer for measurement of energetic charge-exchanged neutrals in Alcator C-Mod", Rev. Sci. Instrum. 77, 083501 (2006).

33. J. L. DeCiantis, J. A. Delettrez, . P. Regan, V. A. Smalyuk, V. Yu. Glebov, J. P. Knauer, F. J. Marshall, D. D. Meyerhofer, S. Roberts, T. C. Sangster, C. Stoeckl, K. Mikaelian, H. S. Park, H. F. Robey, F. H. Séguin, J. A. Frenje, C. K. Li, J. R. Rygg, and R. D. Petrasso, "Proton core imaging of the nuclear burn in inertial confinement fusion implosions", Rev. Sci. Instrum. 77, 043503 (2006). 


\section{GROUP CONFERENCE PRESENTATIONS DURING THE PERIOD OF THE GRANT}

coauthors.

The following list includes talks by the MIT group and talks by our collaborators with MIT

\section{$9^{\text {th }}$ International Fast ignition workshop, Cambridge, MA (2006)}

t1. R. D. Petrasso et al., "Monoenergetic particle backlighter for radiography and measuring E and B fields and plasma areal density".

t2. C. K. Li et al. "Measuring E and B fields with monoenegetic proton radiography".

$48^{\text {th }}$ APS Annual Meeting of the Division of Plasma Physics, (30 Oct. -3 Nov. 2006, Philadelphia, PA)

t3. W. Theobald et al., "High-Areal-Density, Fuel-Assembly Experiments for the Fast-Ignitor Concept," Bull. Am. Phys. Soc. 51, 31 (2006).

t4. P.B. Radha et al., "Inferring Areal Density in OMEGA-DT Cryogenic Implosions," Bull. Am. Phys. Soc. 51, 106 (2006).

t5. J.A. Frenje et al., "Diagnosing Cryogenic D2 and DT Implosions at OMEGA using chargedparticle spectrometry," Bull. Am. Phys. Soc. 51, 106-107 (2006).

t6. F.H. Seguin et al., "Using Target Shimming to Compensate for Asymmetric Drive in ICF Implosions," Bull. Am. Phys. Soc. 51, 107 (2006).

t7. G. Kyrala et al., "The Effect of High-z Impurities on Implosions and Burn in SIO2 Shells," Bull. Am. Phys. Soc. 51, 107-108 (2006).

t8. J. Benage et al., "Spectroscopic Measurements of ICF Capsules Doped with Hi-Z Impurities," Bull. Am. Phys. Soc. 51, 108 (2006).

t9. D.T. Casey et al., "Diagnosing Cryogenic DT Implosions at OMEGA and the NIF using Magnetic Recoil Spectrometry (MRS)," Bull. Am. Phys. Soc. 51, 142 (2006).

t10.R.P.J. Town et al., "Proton Deflectometry of Electric and Magnetic Fields," Bull. Am. Phys. Soc. $\underline{51}, 142(2006)$.

t11.C.K. Li et al., "Measuring E and B Fields in Laser-Produced Plasmas through Monoenergetic Proton Radiography”. Bull. Am. Phys. Soc. 51, 143 (2006).

t12.R.D. Petrasso et al., "Monoenergetic Particle Backlighter for Radiography and Measuring E and B Fields and Plasma Areal Density". Bull. Am. Phys. Soc. 51, 143 (2006).

t13. N.D. Delamater et al., "Design of an Omega Experiment to Diagnose Ablator Burn-through with D-He3 Proton Yield and Spectra," Bull. Am. Phys. Soc. 51, 212-213 (2006).

t14. M. Manuel et al., "Simulation of Monoenergetic Proton Radiography Images of ICF Hohlraums and Capsules," Bull. Am. Phys. Soc. 51,218 (2006).

t15. G.A. Chandler et al., "CR39 Based Neutron Yield Measurements on the Z-Accelerator," Bull. Am. Phys. Soc. 51, 219 (2006).

t16.S.G. Glendinning et al., "Progress in Laser-Driven Dynamic Hohlraum Implosions," Bull. Am. Phys. Soc. 51, 265 (2006).

t17.D.D. Meyerhofer et al., "Studies of Adiabat Shaping in Direct-Drive, Cryogenic-Target Implosions on OMEGA," Bull. Am. Phys. Soc. 51, 340 (2006).

t18. A. Miles et al., "Numerical Simulations of thin-shell direct-drive OMEGA capsule implosions," Bull. Am. Phys. Soc. 51, 341 (2006).

\section{$16^{\text {th }}$ High-temperature plasma diagnostics, (Invited) Williamsburg, Virginia (2006)}

t19.C. K. Li et al., "Monoenergetic proton backlighter for measuring E and B fields and for radiographing implosions and high-energy density plasmas". 
t20.D. Casey et al., "The Magnetic Recoil Spectrometer (MRS( Neutron Shielding and Collimator Design on OMEGA and the NIF".

\section{$36^{\text {th }}$ Anomalous Absorption, Jackson Hole, Wyoming (2006)}

t21. R. D. Petrasso et al., "Monoenergetic particle backlighter for radiography and measuring E and B fields and plasma area density".

t22. C. K. Li et al. "Monoenergetic proton radiography of E and B fields".

\section{REFERENCES}

The following list of references includes many papers written by the MIT group; for more, see http://psfcwww2.psfc.mit.edu/physics_research/hedp/Papers/Papers.html). Black entries are by MIT as either first authors or co-authors. Blue entries are by other authors.

1. J. D. Lindl, Inertial Confinement Fusion (Springer-Verlag, New York, 1999).

2. S. W. Haan et al., Phys. Plasmas 2, 2480 (1995).

3. F. H. Seguin et al., Rev. Sci. Instrum. 74, 975 (2003).

4. F. H. Séguin et al., Phys. Plasmas 9, 3558 (2002).

5. F. H. Séguin, Bull. Am. Phys. Soc. 47 (2002).

6. R. D. Petrasso et al., Phys. Rev. Lett. 90, 095002 (2003).

7. C. K. Li et al., Phys. Plasmas 10, 1919 (2003).

8. F. H. Séguin et al., Bull. Am. Phys. Soc. 48, 57 (2003).

9. C. K. Li et al., Phys. Rev. Lett. 92, 205001 (2004).

10. J. A. Frenje et al., Phys. Plasmas 11, 2798 (2004).

11. P. W. McKenty et al., Phys. Plasmas 11, 2790 (2004).

12. T. C. Sangster et al., Bull. Am. Phys. Soc. 49, 61 (2004).

13. J. A. Frenje et al., Rev. Sci. Instrum. 72, 854 (2001).

14. J. A. Frenje et al., Proposal \#DE-FG03-03NAS00058.

15. J.A. Frenje et al., "A magnetic recoil spectrometer (MRS) for absolute measurements of the neutron spectrum from which $\rho \mathrm{R}$, Ti and yield can be inferred for cryogenic DT implosions at OMEGA and the NIF", in preparation for submission (2007).

16. D.T. Casey et al., "Background characterization and reduction for the Magnetic Recoil Spectrometer (MRS) at OMEGA and the NIF", in preparation for submission (2007).

17. R. D. Petrasso et al., Phys. Rev. Lett. 77 (13), 2718 (1996).

18. J.R. Rygg et al., "Dual nuclear product observations of shock collapse in inertial confinement fusion", submitted to Phys. Rev. Lett. (2007).

19. J. R. Rygg et al., Phys. Plasmas 14, 056306 (2007).

20. D. C. Wilson et al., Phys. Plasmas 11, 2723 (2004).

21. J. R. Rygg et al., "Dual nuclear product observations of shock collapse in inertial confinement fusion", submitted to Phys. Rev. Lett. (2007).

22. J. R. Rygg et al., Phys. Plasmas 13, 052702 (2006).

23. F. H. Séguin et al., Rev. Sci. Instrum. 75, 3520 (2004).

24. F. H. Seguin et al., Phys. Plasmas 13, 082704 (2006)

25. F. H. Seguin et al., "Target shimming for control of ICF implosion symmetry", in preparation for submission (2007).

26. C. K. Li et al., Phys. Rev. Lett. 89, 165002 (2002).

27. J. L. DeCiantis et al., Rev. Sci. Instrum. 77, 043503 (2006).

28. D.A. Callahan et al., Nucl. Inst. Methods A 544, 9 (2005).

29. S. Skupsky et al., Phys. Plasmas 11, 2763 (2004). 


\section{APPENDIX: STATEMENT OF WORK}

A. High resolution neutron spectroscopy for $\rho R$, Ti, and Yield at the NIF and at OMEGA (with LLE, LLNL, LANL, and SNL)

Task A1: Assemble the spectrometer (called the Magnet Recoil Spectrometer, or MRS) and interface to OMEGA. Begin MRS qualification and commissioning.

Task A2: Test, debug, and calibrate the MRS with 14.1-MeV neutrons from noncryogenic and cryogenic DT implosions. Measure absolute yield and Ti with high accuracy.

Task A3: For DT cryogenic implosions in the range $\rho \mathrm{R} \sim 100$ to $200 \mathrm{mg} / \mathrm{cm}^{2}$, measure $\rho \mathrm{R}$ with both charged-particle diagnostics and the MRS; cross calibrate. Finish the MRS qualification.

Task A4: Measure $\rho$ R for cryogenic DT implosions with $\rho R>200 \mathrm{mg} / \mathrm{cm}^{2}$.

\section{B. Direct drive implosion dynamics and mix at OMEGA (also with LLE and LLNL)}

Task B1: Measure shock and compression burn rate magnitudes for a variety of $\mathrm{D}^{3} \mathrm{He}$ implosions with differing $\mathrm{D}_{2}-{ }^{3} \mathrm{He}$ fuel mixtures; compare these absolute measurements to simulations.

Task B2: Measure the DD and $\mathrm{D}^{3} \mathrm{He}$ burn rates simultaneously for optimized mixtures of $\mathrm{D}^{3} \mathrm{He}$. Contrast to simulations.

Task B3: Study Ti(t) in the compression region for a variety of implosions using the ratio of DD and $\mathrm{D}^{3} \mathrm{He}$ burn rates. Contrast results to simulations.

Task B4: Study $\rho R$ and $\rho R$ asymmetry evolution, especially at shock and compression bang time, using the proton spectrometers. Compare to simulations.

C. Imaging nuclear burn with implosion fusion protons (also with LLE and LLNL)

Task C1: Utilizing $\mathrm{D}^{3} \mathrm{He}$-filled capsules, measure burn radii of implosions of various types for study of fuel-shell mix and integrated implosion dynamics.

Task C2: Study effects of drive asymmetry on burn asymmetry for various capsule types.

Task C3: Attempt to use shimmed targets in order to explore burn asymmetries, and as a means to compensate for laser drive asymmetries.

\section{Indirect drive studies at OMEGA (also with LLNL and LLE)}

Task D1: Study (with proton spectrometers) the $\rho$ R and yields associated with shock and compression burns for hohlraum implosions.

Task D2: Compare experimental results to simulations.

Task D3: Attempt to determine the magnitude of B fields associated with hohlraums.

\section{E. Graduate and undergraduate student training, education and research}

Task E1: Recruit and train students at $\mathrm{PhD}$ and undergraduate levels; stimulate them with challenging problems in ICF, nuclear physics, and high-energy-density physics.

Task E2: Give students hands-on experience with nuclear techniques using small-scale experiments at MIT as well as the experience of collaborating with physicists at LLE, LANL, LLNL, SNL, and GA.

Task E3: Have students present their research at MIT and LLE seminars, at National Laboratory workshops and seminars, and at national conferences. 